\title{
Architecture Students Participation in Competitions as a Tool for Resilience Architecture Education in Egypt
}

\author{
Ahmed Haron \\ MTI University, Faculty of Engineering, Cairo 10858, Egypt.
}

ORCID: 0000-0002-2452-8841

\begin{abstract}
Architecture competitions today are considered to be a vital part of the architecture market at national and international levels. One of the main targets of the education process is to prepare graduates and provide information and skills to meet market needs. Theories emphasize that competitiveness improves creative abilities and produces a better product work. Architecture design became a thriving market on the move that is not defined with geographical boundaries. The preparation of an architect who can compete locally and globally has become an urgent need and a major goal of various educational institutions. This research raises several questions about the role of architecture competitions in developing the skills of architecture students in the Egyptian education system. It highlights the positive or negative impacts of participation in competitions. What are the possibilities and benefits that result from participation in this process? What is the difference between the point of view architecture students at the bachelor and graduate levels vs. the views of faculty teaching staff?, towards introducing new frameworks to develop the Egyptian architectural education and keep pace with the global educational systems that combine theoretical academic education with the simulation of the practical reality in the market.
\end{abstract}

Keywords: Architecture Education -Competition - Market Egypt

\section{RESILIENCE EDUCATION}

The concept of resilience education changes according to the context used and according to the historical period in which this term was used. In the classic case, this term is used in the face of natural disasters and emergency conditions to transform the educational process into a flexible process in terms of location and timing (Neill, J. T., \& Dias, K. L,2001). With the development of communication the world turning into digital education, the concept of resilience learning has increased. As it became the expression of education without borders and no obstacles using new communication methods and digital tools. This definition moved to be the concept of unlimited education (Hersh c. Waxman and others 2003) without fixed regulations except to maintain the general framework for the type of study and its outputs.
Education moves from the concept of the initiation process between the teacher and the student. Into a complex nested process. Many factors and stakeholders are involved (Martin Weller and Terry Anderson, 2013) like companies, destinations, and institutions.

Under this structure, the importance of the transition from traditional architectural education to resilience education is evident. It is necessary to linking education in Egypt with more flexible and dynamic techniques.

\section{COMPETITIONS DEFINITIONS, IDEA AND PRACTICES}

The word competition in the language is defined as "an activity done by some people or organizations, each of which is trying to do better than all of the others (Cambridge 2019). But Deutsch defined it as "a setting in which the goal attainment of participants is negatively linked so that the success of one participant inherently comes at the failure of the other". The definitions and classifications varied according to each area where competitions are defined in business as "the situation in which people or businesses are trying to be more successful than each other", for example by making more sales in a market. Most of the definitions describe the competition as a positive action aimed at achieving the highest benefit / best production to reach the highest return (economic - social - environmental - moral . etc). This positive action is part of human life. That way of actions put him in the wise creatures on earth; during his journey to achieve development on the earth. This action/competition is a group or individual activity that depends on direct and mutual benefits. These activities then crystallized into a lifestyle and between communities and institutions(Juan Carlos Burguillo 2010).

Recent studies show that people in competitiveness/competitions exceed their limited abilities and show greater potential for victory in a competitive state between a clear group and honest roles (Gavin J. Kilduff and others 2010). And the biggest evidence of that is the ability of athletes to break records. Even the same athlete can land his record more than once. This comes under new conditions that stimulate competition and excellence and emphasizes the infinite capabilities of excellence and creativity in humans provided the existence of a successful catalyst and the specific rules of measurement. 


\section{COMPETITIONS IN THE ARCHITECTURE MARKET}

In architecture, market customers are always looking forward to the creative and influential production. The main purpose of architectural competitions: getting the best ideas available in addition to having more than one alternative and one idea per project (Hamzah Al-Mamoori 2019). In addition to the important economic factor, the target is to get this huge amount of ideas and proposals without spending large amounts on more designers or architectural offices. Contests may become a promotional element for the project itself before it begins. This added value could be used in the future marketing of the services, products or spaces provided by the project like real estate projects and airport design. In national projects, architectural competitions may become a symbol of excellence for the country or city. This is reflected in major world events such as the World Expo, the Olympic Games or the FIFA World Cup.

Architecture competitions no longer contest as a special field of professional excellence, but also reflect many other fields like research, development, and teamwork and globalization work environment. For that Dinç defined architecture competitions as "a production environment where the values are reconstructed and questioned. It can mobilize creative forces simultaneously and acknowledge the proposals that can be distinguished from the others, and thus enable the original solutions to participate in life. (Mustafa OrkunÖzüer, PınarÖktemErkartal 2019).Competitions have been transformed into existing institutions in the architectural market. These institutions work to develop the creative and cognitive production of the architectural design process. These institutions work to achieve the common success of all parties involved in this competitive process. (Joseph Lampel and others 2014) Competitions have shifted from the pursuit of excellence in some projects to a permanent need in the architectural market for all parties of the process of design and implementation. Need for the clients who search for the best architectural and economic solutions for the project. It is a Need for architects to show their creativity and marketing themselves. It also a need for society to participate actively in the decision-making process, especially in public projects. ( Reidunn Rustad 2009)

Several studies have confirmed that, according to ( Jonas E Andersson 2014, Iraqi 2019, Joseph Lampel 2014 ), the increase in architectural precedents has increased the creativity and productivity of the architectural market at both the quantitative and qualitative levels.

\section{ARCHITECTURE EDUCATION IN EGYPT}

The architecture educational system in Egypt depends on the rules and standards set by the central government. All educational institutions working in this field are subjected to these rules. On top of these institutions there are four major bodies; the Supreme Council of Universities, which is responsible for the affairs of public universities, private and national universities council, which heads these universities. The Supreme Council of Private Institutes all higher institutes, academies under that council, and the Council of which Technological Colleges are governed. These four institutions are headed by the Minister of Higher Education and Scientific Research (Ministry of Higher Education 2019).there are 27 public universities in Egypt plus 24 private universities, they all include departments of architecture engineering and urban planning (Ministry of Higher Education, 2018) that is providing more than 60 architecture undergraduate programs and 35 postgraduate programs in addition to 47 private institutes that have special undergraduate architecture programs (Egyptian Engineers Syndicate, 2019)

According to statistics of the Egyptian Engineers Syndicate which is responsible for the practice of architects' profession in Egypt, there are more than 5000 graduates every year that majored in architecture, urban planning, and urban design from Egyptian universities and high institutes'. They are directly registered in the union's tables. They must entitle to practice the profession under registered architect supervision for two years. After that, they are entitled to practice the profession without supervision (Egyptian Engineers Syndicate, 2019).

According to the Egyptian higher education system, the study in architecture programs within the framework of the faculties of engineering must include 5 years of study. The first year is considered as a preliminary year that includes general majors of all the departments of engineering after that, students could major in architecture or any other department of engineering starting from the second year of study. Study regulations in the departments of architecture are divided into two basic systems, the mainstream system which is accredited in all public universities in addition to more than 20 private institutes, and the credit hours system which is accredited in all private universities and 10 state-funded universities and about 27 private institutes and academies (Ministry of Higher Education 2018)

The average number of credit hours studied by the student is 160:175 credits in the credit hour programs. The average is 65 subjects (Cairo University, Ain Shams University Modern, October, and others, 2019) for 10 semesters. For graduate studies, the courses of the Master's degree are 21 credit hours in addition to the Master's degree, in a maximum of 8 semesters. These figures vary by the increase or decrease according to each University's rules and bylaws. Compared to the higher education systems in international universities, we find that in terms of form, the Egyptian regulations are compatible with international systems. Besides, more than one program in Egypt has received international accreditation. Some students in other programs obtained two degrees from the Egyptian University and a European University. Source (Ain shamas University, MSA University, and others). That means in regulation level the Egyptian systems for architecture studies are compatible but the final result of education level related to performance and applications.

\section{METHOD}

The investigation method was based on a theoretical study for education systems and two online questionnaires to 
International Journal of Engineering Research and Technology. ISSN 0974-3154, Volume 13, Number 7 (2020), pp. 1610-1615

(C) International Research Publication House. https://dx.doi.org/10.37624/IJERT/13.7.2020.1610-1615

participants in the education process. The first form was sent to architecture students in 6 Egyptian universities between 15 May 2019 and 15 June. The second questionnaire sent to groups of academic staff in the same universities from 16 June to 16 July 2019.

\subsection{Student Questionnaire}

The students were surveyed on the subject of participation in student competitions and their positive, negative impact and feedback. The questionnaire was sent to 60 students. 44 students responded representing $73.3 \%$ of the target group. The results were as follows

The percentage of students who participated in architecture competitions in the past two years was 27 students, $61.4 \%$ of the student population. $44.4 \%$ of them participated in more than one competition in various fields as shown in Fig. 1.

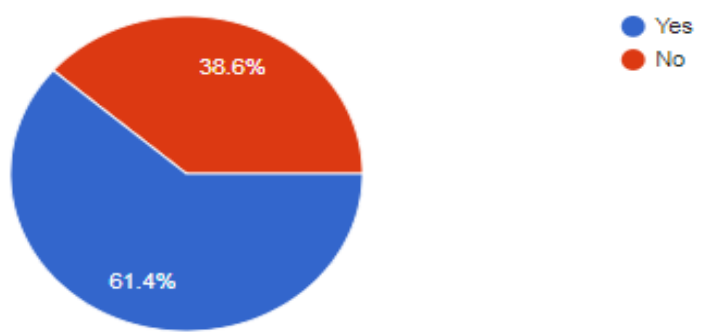

Fig. 1

From the students' point of view, answers about benefits gained from the competitions. They informed that they learned new skills and knowledge, had not studied in their courses. Also, they endorsed that varying averages increased their skills and knowledge in many of their subjects. Fig (2) shows the list of skills they learned or develop it throw participation in competitions.

When asked about the role of the faculty staff and the extent of their participation with students in these activities, $75 \%$ stressed the positive impact of the faculty member in their participation and motivation. When measuring the responses of students who did not participate and why they did not participate, the answer of $73.9 \%$ of them that they do not have enough time in addition to more than $30 \%$ confirmed that no competition was offered to them nor were they motivated enough to participate.
Table 1.

\begin{tabular}{l|c}
\hline List of Skills & Percentage of needs \\
\hline Computer Skills & $70.5 \%$ \\
Presentation Skills & $52.3 \%$ \\
Team Management & $50 \%$ \\
Informed skill & $45.5 \%$ \\
\hline
\end{tabular}

When all participants were asked what skills they would like to add to the study programs to help them participate effectively, the answers were as follows:

About $86.4 \%$ confirm that there is no time available for the student to participate in these activities. In addition to the lack of workshops and training programs and other reasons like motivations, advanced labs and digital environment in school. They most need moral encouragement funds and the addition to grades in courses related to competitions and on student activity.

In general, students unanimously agree on the importance of participating in architectural competitions, as a requirement in the professional market and an innovative competitive method. In addition to their consensus on the lack of an environment that allows them to participate and learn at the same time, for many reasons, some of which were mentioned.

\subsection{Academic Staff Questionnaire}

The second questionnaire was sent to the professors of architecture and faculty assisting members in six universities included in the first questionnaire from 16 June to 16 July 2019. The questionnaire was sent to 40 faculty members and 21 members responded representing $52.5 \%$ of the target group. Demographic information Table (2)

Respond to Academics when asked about the importance of participating in competitions for students and its role in developing students' skills and preparing them for the professional market. The average answer was more than 90.5\% positive. This reflects the extent to which the role of the competitions is confirmed. However, the percentage of professors who participated in supervising in student competitions during the previous two years was $52.4 \%$. the types of previous competitions students participated in.

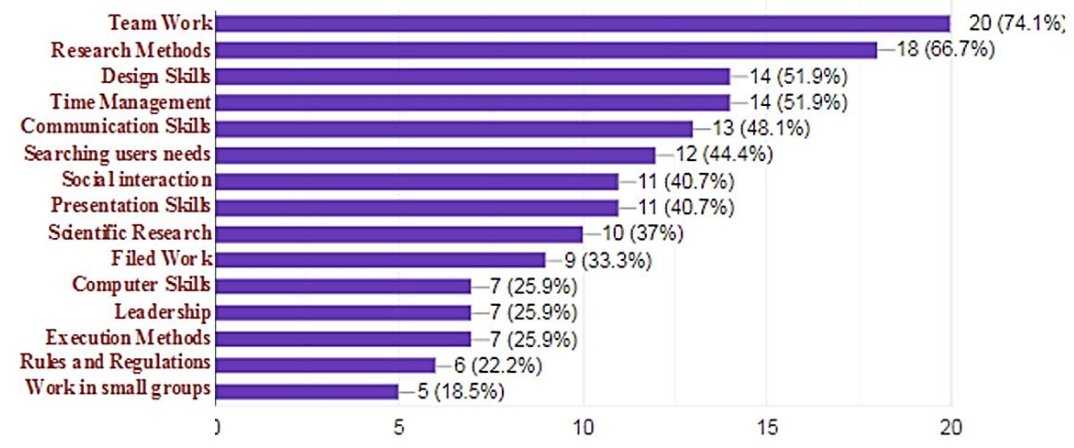

Fig. 2 
International Journal of Engineering Research and Technology. ISSN 0974-3154, Volume 13, Number 7 (2020), pp. 1610-1615

(C) International Research Publication House. https://dx.doi.org/10.37624/IJERT/13.7.2020.1610-1615

Table 2: Academic Staff Demography

\begin{tabular}{|c|c|c|c|c|c|c|c|}
\hline \multicolumn{2}{|l|}{ Gender } & \multicolumn{2}{|l|}{ Age } & \multicolumn{2}{|l|}{ Degree } & \multicolumn{2}{|l|}{ Academic Position } \\
\hline Male & $28.6 \%$ & $26: 30$ & $33.3 \%$ & Bachelor & $9.5 \%$ & Teaching Assistant & $14.3 \%$ \\
\hline \multirow[t]{4}{*}{ Female } & $71.4 \%$ & $31: 35$ & $31.35 \%$ & Masters & $28.6 \%$ & Assistant Lecturer & $23.8 \%$ \\
\hline & & $36: 40$ & $9.5 \%$ & Decorate & $61.9 \%$ & Assistant Professor & $23.8 \%$ \\
\hline & & $\geq 40$ & $42.9 \%$ & & & Associate Professor & $23.8 \%$ \\
\hline & & & & & & Professor & $14.3 \%$ \\
\hline
\end{tabular}
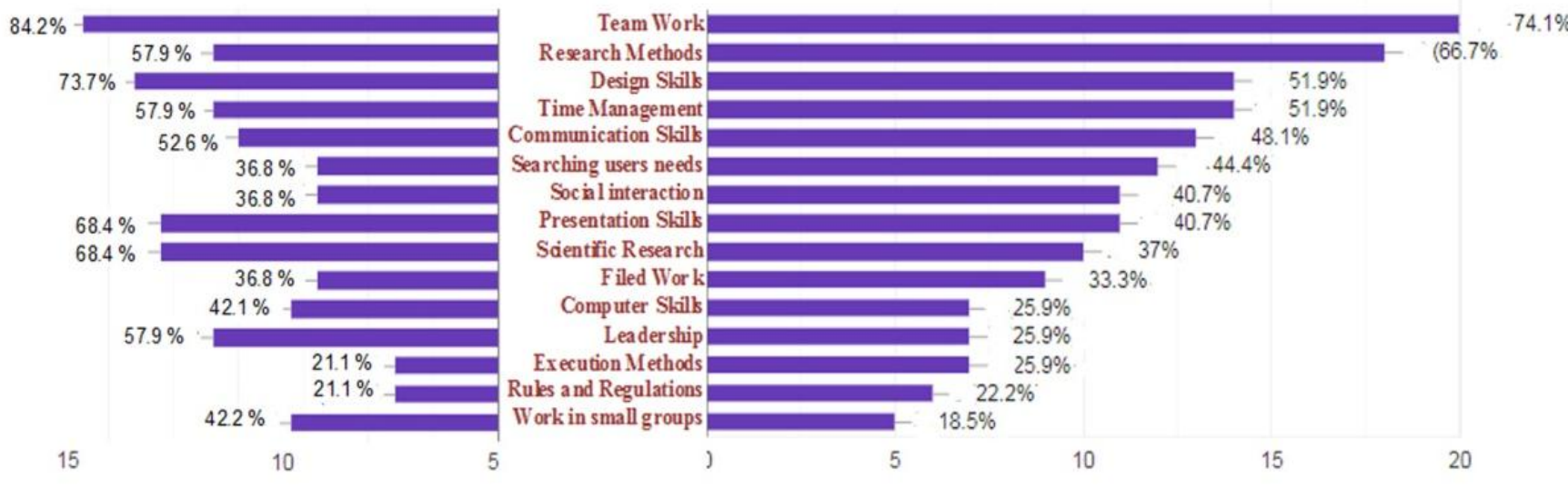

Fig. 3: Academic staff point view vs. Student

Academic staff who did not participate in any competitions during the previous years explained the reasons for not participating; the answers were varied but reflect the real needs to be taken into account in the academic system of the departments of architecture. 54.6\% of them informed that they do not have enough time to manage these activities, $18.2 \%$ need the motivation to participate also $45.5 \%$ of them said no competition fits them skills!

In answers about skills, the student learned from participation in competitions $100 \%$ endorse that student learns a lot of skills from participation fig (3) shows the skills learned from student and academics point views.

By comparing both points of view of the students and academic staff. We find a gap between the opinions of students and teachers. Also, the gap between the needs of students and the market compared with courses offer inside schools (Jacqui Weetman DaCosta, 2010).

\section{DISCUSSION}

For the education system to be effective, it must meet the psychological and material needs of all parties participating in the educational process (John Worthington And Aylln Orbasli, 1996). At the same time, it achieves targeted results for stakeholders.
Therefore, the educational process must be an interactive process from the inside between the student and the teacher. At the same time, it is a dynamic process between the university and its laws and curricula on the one hand, and the practical market and user needs on the other. To develop this process (Stephen Sterling 2009). it is necessary to understand its dimensions, bridge the gaps between the parties involved (Alexander W. Astin1999), and understand the reality to achieve the educational development goals.

Therefore, fig (3) represents the difference between the views between the teacher and the student in the set of skills that he or she acquires from study or competitions while the professors emphasize that their students acquire a lot of skills and knowledge during their participation in the competitions. And they did not acquire these skills with the same ability in the academic programs inside the university. As shown in fig (4). More than $85 \%$ of the professors confirmed that the development of their students 'performance after their participation in the various competitions. Despite this, there are no curricula or motivating factors for students to participate in these activities in the academic programs in these colleges according to $95 \%$ of the participating faculty members. This reflects the gap between the academic content and the teaching list with the reality that the student and the teacher touch alike. 


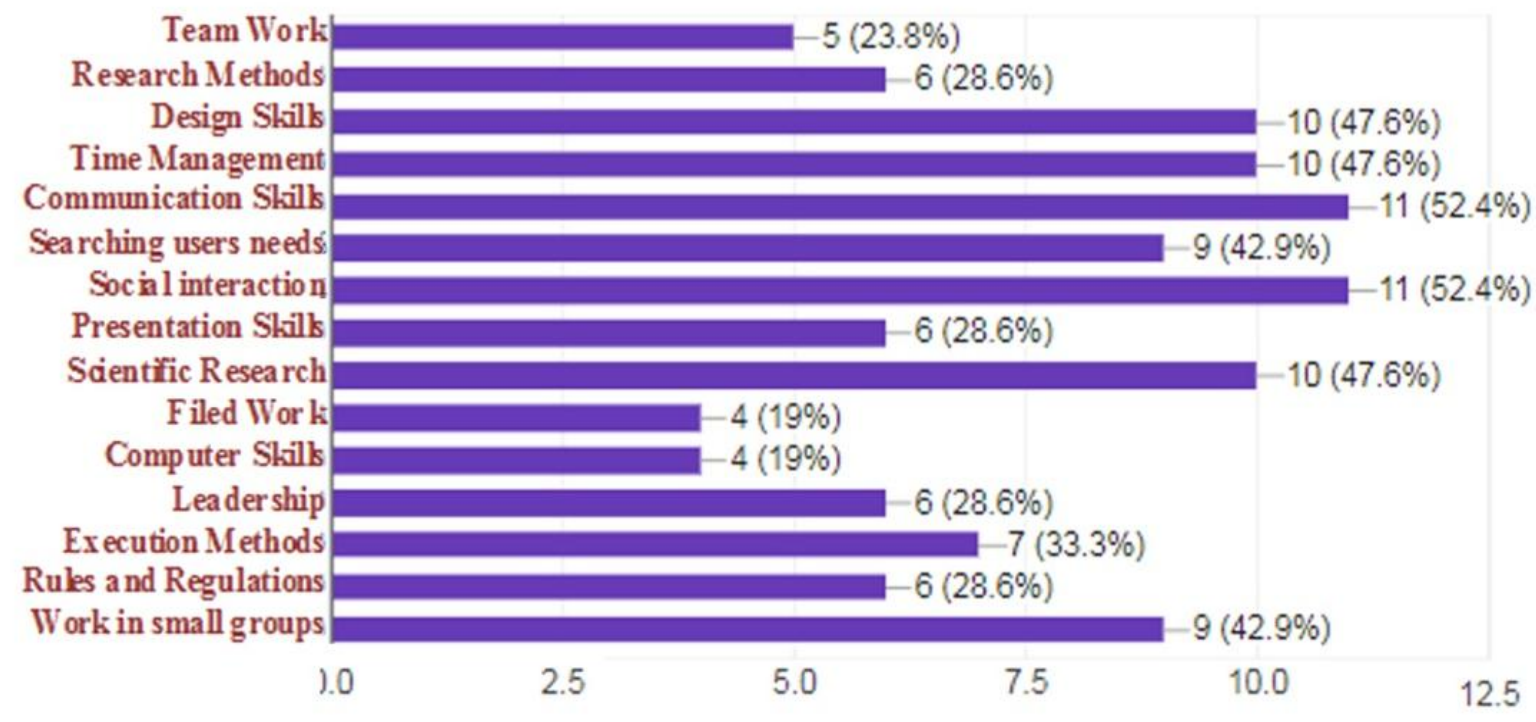

Fig. 4: Students skills development after participation in competitions from Academic staff point view

\section{RESULTS}

The study emphasized the role of Architecture student competitions in developing students' performance and increasing their skills and to what extent the architecture market in Egypt needs to increase these types of competitions to help create and raise efficiency and competitiveness.

The study concluded that the curricula in the departments of architecture in Egyptian universities need to have the required subjects (Ashraf M. Salama, Abdulgader Amir.2005) Also, there are materials in which competitions are allowed to be part of the student interaction with the future job market.

While the results of the study confirmed the extent of faculty members understand the role played by student competitions in the development of skills and knowledge of their students, but they lack a lot of potential and time to activate this role.

The study concluded that there are no suitable times in the study schedules for practicing such activities and there is no free time for the university professor to practice these activities with his students during the school day. This forces most professors to work longer periods and without financial or moral volunteers to help their students in the activity.

The study emphasized the role played by competitions in the development of creativity and increase the quality associated with the final architectural product according to previous studies in theory and practice.

The study also stressed that the professional practice field needs graduate architects who have experienced competition and teamwork before joining companies.

As for the skills, the study emphasized that learning soft skills is increasing for students participating in the competitions, whereas such curricula and courses do not have such skills. The graduate always relies on individual learning or experience. As for computer skills and specialized programs, the study confirmed that most of the skills of arithmetic were taught by students outside the framework of the curriculum. Allowing time and linking activities to degrees and financial and moral incentives were the most important needs requested by the professor and the student to the extent to activate this integrated system.

\section{RECOMMENDATIONS}

For universities and academic board Developing regulations to cope with market mechanisms and real needs in terms of the content of the subjects and the number of courses and types of materials that help creativity and application

Increasing the application of materials applied to the theory and workshop rates and practical training on the theory to link students with the actual skills and applied in the professional market.

Allow time for students and professors to practice activities and link them to the level of quality and degrees of activity with the presence of material and moral incentives for students and professors.

Increasing the capabilities of the laboratories and the trained human resources and qualifying the teaching staff and their assistants to develop their skills to cope with the digital revolution in the market of architectural and urban design and implementation. To achieve the goals of this educational process must Continuity of surveys with all stakeholders in the educational process for architectural students.

Involving the architectural offices and companies in drawing up lists of skills and knowledge needed in the market. These skills and knowledge could be part of the guidelines on which architectural curriculum developers depend. 
International Journal of Engineering Research and Technology. ISSN 0974-3154, Volume 13, Number 7 (2020), pp. 1610-1615

(C) International Research Publication House. https://dx.doi.org/10.37624/IJERT/13.7.2020.1610-1615

\section{REFERENCES}

[1] Neill, J. T., \& Dias, K. L. Adventure Education and Resilience: The Double-Edged Sword. Journal of Adventure Education and Outdoor Learning, 1(2), 3542. (2001).

[2] Hersh c. Waxman, Jon p. Gray and Yolanda n. Padrón." review of research on educational resilience", center for research on education, diversity \& excellence, University of California. 2003, USA.

[3] Martin Weller and Terry Anderson," "Digital resilience in higher education. European Journal of Open, Distance, and e-Learning - Vol. 16 / No. 1, 2013, UK.

[4] Burguillo, J.C. Using Game-Theory, and Competitionbased Learning to Stimulate Student Motivation and Performance, Computers \& Education, 2010.

[5] Gavin J. Kilduff, Hillary Anger Elfenbein, and Barry M. Staw." The Psychology of Rivalry: A Relationally Dependent Analysis of Competition", Academy of Management Journal, Vol. 53, No. 5, 943-969. 2010

[6] Hamzah Al-Mamoori .," The Role Of Competitions In Architectural Design And Creativity". Advancements in Civil Engineering and Architecture, Volume 2: Architecture, the International Civil Engineering \& Architecture Conference, 2019, Turkey.

[7] Mustafa OrkunÖzüer, PınarÖktemErkartal.” Designing The New Into The Old: Architectural Design Competitions For Historical Context." Advancements in Civil Engineering and Architecture, Volume 2: Architecture, the International Civil Engineering \& Architecture Conference, 2019, Turkey.

[8] Joseph Lampel, Pushkar P Jha, and Ajay Bhalla," TestDriving The Future: How Design Competitions Are Changing innovation. ".Winning Ideas, Chartered Management Institute2014, UK.

[9] Reidunn Rustad ." What is Contemporary Architecture? Changes in Architectural Competitions and Architectural Discourse." Nordic Journal Of Architectural Research., Vol. 21, No 2/3.2009.

[10] Jacqui Weetman DaCosta.'Is There an Information Literacy Skills Gap to Be Bridged? An Examination of Faculty Perceptions and Activities Relating to Information Literacy in the United States and England." College \& Research Libraries. Association of College \& Research Libraries. 2010.

[11] John Worthington And Aylln Orbasli, "The Assessment of the Role of Practice in Architectural Education: A European Comparison." 84th ACSA ANNUAL MEETING.1996

[12] Stephen Sterling." Learning for resilience, or the resilient learner? Towards a necessary reconciliation in a paradigm of sustainable education." Environmental Education Research. Vol. 16, Nos. 5-6, 511-528 .2009.

[13] Alexander W. Astin." Student Involvement: A Developmental Theory for Higher Education". Journal of College Student Development. VOL 40 No 5. 1999.
[14] Ashraf M. Salama, Abdulgader Amir. "Paradigmatic Trends in Arab Architectural Education: Impacts and Challenges ." UIA Congress 2005, Turkey.

[15] http://scu.eg/pages/organizational_structure

[16] http://eea.org.eg/PageDetails.aspx?ID=305

[17] http://naqaae.eg/?page_id=972

[18] http://arch.eng.cu.edu.eg/

[19] https://msa.edu.eg/msauniversity/engineering 